\title{
Homossexualidades projetadas
}

\section{A personagem homossexual no cinema brasileiro.}

MORENO, Antônio.

Rio de Janeiro: FUNARTE/ EDUFF, 2001.

Os debates recentes sobre identidade coletiva têm, entre outros temas, enfatizado os modos como os grupos minoritários são afetados por imagens veiculadas sobre eles nos diferentes meios de comunicação. Isso se deve ao reconhecimento do fato de que as diferentes instituições da mídia detêm uma enorme capacidade de criar verdades sobre coisas e grupos sociais que circulam entre nós. Se é verdade que, de um lado, tais instituições podem colaborar para a estruturação de condições emancipatórias de grupos minoritários, de outro, elas podem agir de forma deletéria, contribuindo para a não-construção de identidades coletivas politicamente fortalecidas. Tomando a mídia televisiva como exemplo, Pierre Bourdieu examina essa questão nos seguintes termos: "Os perigos inerentes ao uso ordinário da televisão devemse ao fato de que a imagem tem a particularidade de poder produzir $\circ$ que os críticos literários chamam o efeito real; ela pode fazer ver e fazer crer no que faz ver. Esse poder de evocação tem efeitos de mobilização. Ela pode fazer existir idéias ou representações, mas também grupos. As variedades, os incidentes ou os acidentes cotidianos podem estar carregados de implicações políticas, éticas, etc. capazes de desencadear sentimentos fortes, freqüentemente negativos, como o racismo, a xenofobia, o medoódio do estrangeiro, e a simples narração, o fato de relatar, to record, como repórter, implica sempre uma construção social da realidade capaz de exercer efeitos sociais de mobilização (ou de desmobilização)."'

O campo dos estudos homossexuais no Brasil, apesar do seu desenvolvimento nos últimos anos, ainda explorou muito pouco da reflexão apontada acima. Essa lacuna vem sendo lentamente preenchida por estudos como o de Antônio Moreno. Em trabalho de acabamento luxuoso, ele revela como a figura do homossexual é construída na filmografia nacional. O seu universo de análise são filmes de longa metragem produzidos em nosso país desde a década de 1920. Muito corretamente, Moreno os entende tanto como produtores de imagens e verdades quanto como amálgamas de crenças vigentes em nossa sociedade. Em tais filmes, como ele afirma, pode-se encontrar "uma pintura em movimento do gay e da lésbica" (p. 25).

Para a realização do estudo, ele desenvolveu um modelo de análise fílmica que o permitiu apreender a gestualidade e a narratividade recorrentes na construção dramática das diferentes películas examinadas, ao mesmo tempo em que possibilitou a demarcação de "um conjunto de valores conferidos ao sujeito analisado pela produção cinematográfica [o qual] delimita a sua importância e participação quanto à sua imagem, status e representatividade dentro da sociedade em que vive" (p. 162).

Moreno identifica três fases da representação do homossexual no cinema nacional. Na primeira fase, que vai da década de 1920 até o início da década de 1960, ele sugere que o tema era um tabu de tal ordem que os homossexuais mesmo quando presentes não eram vistos como tal. Comentando essa questão ele afirma que "As referências ao homossexualismo, até então, eram poucas, a não ser pela estética de alguns filmes, ou momentos indiciais de sua presença (...) ou de maneira muito velada (...) O tema era tão tabu que nem mesmo se permitia ao público imaginar tal tipo de comportamento. Era como se o homossexualismo não existisse. Embora houvesse a sociedade fingia não perceber. E o cinema seguia a regra (...)" (p. 26). Nessa fase, além de pouco explícita, a homossexualidade era todo o tempo associada ao domínio do risível realçado por um toque efeminado nos trejeitos e vozes dos personagens. Uma segunda fase, iniciada na década de 1960, foi marcada por um número maior de películas abordando o assunto. Mesmo assim, sugere Moreno, o crescimento não foi muito significativo, já que a abertura de novas frentes de discussão no cinema brasileiro privilegiou temas sociais e políticos mais amplos. Ao mesmo tempo, à exceção de uma abordagem mais 
explícita, não se assistiu nesse momento a mudanças relevantes na caracterização da homossexua-lidade predominante na primeira fase. Já na década de 1970, início da terceira fase, ocorre uma explosão de filmes que traziam a questão da homossexualidade em seu bojo. É ali que, dando continuidade às tendências das fases anteriores, se consolida "um modelo de personagem homossexual que vai preponderar nas produções desta e das décadas seguintes, chegando a estender este modelo para diversos meios, como a televisão, através do gestual, e o rádio, através do modelo de voz" (p. 74).

Da análise de filmes de diferentes períodos, Moreno conclui que a tendência majoritária é a de que os homossexuais sejam apresentados como indivíduos doentes e patogênicos em cujas biografias se encontram associações com o crime, a prostituição e o vício. Paralelamente, eles são, de forma jocosa, apresentados como indivíduos portadores de uma gestualidade excessiva e adeptos do uso de vestuários extravagantes, assim ratificando a sua condição de palhaço e objeto de cachota. Outrossim, o tipo ideal do homossexual apresentado - com grande freqüência um travesti - possui baixo nível de escolaridade, mora em habitações degradadas e é subempregado. Do ponto de vista emocional os homossexuais são apresentados como traiçoeiros, falsos, vingativos e violentos. Não é surpreendente, assim, que o fim deles nos filmes analisados seja predominantemente marcado por tragédia, mortes violentas, depressão, suicídio e miséria. Como o próprio Moreno exemplifica, "em $A$ lira do delírio, Otoniel termina no hospital após ser incendiado; a Marlene [um travesti] de Amor bandido se joga no pátio interno do edifício malfalado, se suicidando; a Geni [um travesti] de Ópera do malandro é assassinada friamente, e com asco, por Tigrão; ou ainda são torturadas, apanham ou morrem das mais diversas formas, como em $O$ anjo nasceu, Navalha na carne, $O$ casamento, A casa assassinada ou em O beijo da mulher aranha, e não se realizam como pessoa" (p. 283).

Um exemplo lapidar desse tipo de descrição encontra-se no filme intitulado A Rainha Diaba (Antônio Carlos Fontoura, 1974) analisado por Moreno em seu livro. Nele, a personagem principal, Diaba, vivida pelo ator Milton Gonçalves, chefia uma gang de homossexuais envolvidos com o tráfico de drogas. Na história os gays são ao mesmo tempo afeminados, exacerbadamente agressivos, cruéis e oligofrênicos. O contexto da existência desses personagens é o de intrigas, traições e vinganças, cujo tom é marcado pela própria denominação da protagonista - Rainha Diaba - e de um dos seus principais ajudantes - Coisa Ruim. O enredo obviamente não poderia conduzir a um fim menos sombrio: a Rainha Diaba tem o seu pescoço cortado por uma navalha. Minutos depois, durante a 'celebração' da sua morte, vários marginais são envenenados e, enquanto seus corpos se amontoam, ela ressurge ainda com vida para atirar na última sobrevivente e assim, matando e morrendo, concluir o seu reinado.

Paralelamente a essa tendência, Moreno também identifica uma representação, minoritária, da homossexualidade marcada por uma abordagem mais humanista da questão, a qual identifica o gay como "um ser que tem direito de escolha sexual" (p. 291). Um dos exemplos que ele aponta dessa orientação é 0 menino e o vento (Carlos Hugo Christensen, 1966). Nesse filme, o contexto social no qual a homossexualidade é apresentada contrasta diretamente com $O$ ambiente de violência no qual se desenvolve $A$ Rainha Diaba. O homossexual protagonista é um engenheiro bem-sucedido financeiramente, interpretado sem traços efeminados ou vestuário extravagante, "de forma natural", de acordo com a classificação de Moreno. O filme trata da relação do protagonista com um garoto que, após despir-se e abraçá-lo, desaparece no alto de uma montanha. $O$ engenheiro, acusado do desaparecimento do menino, é levado a julgamento e ali descreve de forma poética a natureza da sua relação com ele. Por toda a trama o engenheiro é descrito como "ingênuo, puro, [alguém que] não aceita compactuar com tramóias, pois acredita em sua inocência e que vai ser compreendido e absolvido" (p.194). Durante o seu depoimento ele nega qualquer tipo de contato (homo)sexual, enfatizando que a sua relação com o garoto se dava pela beleza do vento que ele representava e invocava. Ao final, em um clima fantástico, uma enorme ventania toma conta do tribunal. Os objetos caem, as pessoas fogem. Sozinho no salão, o engenheiro acha então a camisa do menino. "Ele a apanha. Fica com ela entre as mãos, numa atitude de querer acariciá-la e ao mesmo tempo não, assim como alguém que de repente descobre algo muito intenso sobre si mesmo" (p. 202). Esse momento, na análise de Moreno, representa a 
culminância de um processo de autoconhecimento que levou o engenheiro a reconhecer, estupefato, sua homossexualidade. Diz ele, ainda sobre o engenheiro: " [É] Como se [ele] visse na camisa o vento e o menino, a materialização da natureza, que não se pode matar: sua paixão homossexual, o vento que ele amou e se tornou menino, que é agora somente uma sensação, não existe mais. Mas este mesmo vento trouxe até ele a camisa que foi do menino, para lembrá-lo de que esta sensação em relação ao vento/menino é agora um sentimento que faz parte dele, faz parte da sua natureza" (p. 204). Moreno vê em filmes como esse uma abordagem mais abrangente das relações homoeróticas e uma oportunidade de se problematizar a discriminação social contra a homossexualidade. Contudo, como ele mesmo salienta, essa é uma abordagem minoritária, quase residual, que só com grandes dificuldades pode se erigir como um discurso contrário à caracterização predominante da homossexualidade no cinema brasileiro.

O trabalho de Moreno apresenta, além do ineditismo, uma série de características positivas. Uma delas é o resgate de uma dimensão da memória da subcultura gay brasileira dentro de um período de tempo bastante amplo (19231994). Isso assume uma importância ainda maior ao se pensar nas dificuldades que tal resgate impõe quando se trata de grupos marginalizados. Tais dificuldades se devem, em particular nos estudos sobre as minorias sexuais, ao alto nível de privatização de suas práticas sócio-sexuais e à enorme escassez de registros que permitam uma melhor caracterização dos seus cotidianos ontem e hoje.

Um outro aspecto relevante do livro referese ao fato de que Moreno coloca a representação da homossexualidade no fecundo campo de indagações sobre nossas dificuldades de lidar com a diferença e as tendências presentes em nosso meio de ridicularizar, encobrir ou simplesmente eliminar os diferentes 'outros' étnico-raciais (negros, indígenas, etc.), geográficos (o africano, estrangeiros, orientais, etc.), geracionais (idosos e crianças) e de gênero (travestis, mulheres, transgêneros, etc.) que criamos e recriamos todo o tempo. Ainda que não desenvolva extensamente esse argumento, Moreno salienta que é na construção e nas dificuldades de se lidar com a otherness da homossexualidade que residem as bases psicossociais responsáveis pela reiterada utilização de modelos estereotipados nos filmes analisados. Assim fazendo, produtores e diretores evitam confrontos culturais com um público pouco desejoso em ver o 'outro-homossexual' sob luzes que não aquelas da extravagância e do ridículo. O efeito substantivo mais negativo desse processo obviamente recai sobre o homossexual que, diz o autor, fica então envolto em "uma couraça de invisibilidade que mascara, esconde e não 'descobre a personagem'. Ela, e todo o discurso que a envolve, param no tempo e no espaço. Como uma personagem, sua entrada em cena já denota todas as suas implicações e o público já sabe como vai-se comportar e agir" (p. 285).

No que pesem essas qualidades, o livro apresenta fragilidades teórico-metodológicas que roubaram do autor a possibilidade de desenvolver uma análise mais sofisticada do seu objeto. Uma primeira dessas fragilidades é, exceto pela indicação superficial do surgimento do movimento gay e das limitações políticas e culturais postas pela ditadura militar, a ausência de uma contextualização mínima do conjunto de filmes analisados. Isso deixa o leitor com a impressão de que o aumento da quantidade de filmes e os tratamentos que dão à homossexualidade são criações autônomas de produtores e diretores, descoladas de processos culturais em curso na sociedade brasileira dos últimos 70 anos.

Uma outra fragilidade diz respeito à nãoutilização por Moreno da literatura mais recente do campo dos estudos de gênero, em particular aquela afeta ao homoerotismo. Não que todas as pesquisas sobre o universo gay tenham que se servir dessa orientação. Mas isso teria, possivelmente, feito com que ele evitasse o uso inadequado de categorias e o uso de categorias inadequadas (como a já suficientemente criticada 'homossexualismo'), assim como o teria ajudado a suplantar análises superficiais de temas relevantes - como as dinâmicas de formação dos gêneros e a sexualidade (ver $p$. 32) -, as quais muitas vezes são tomadas em um registro intelectual próximo do senso comum. Teria também o ajudado a não atribuir um caráter de excepcionalidade à presença de homossexuais no mundo público brasileiro nos anos 1950, pois se encontra bem documentado hoje que a circulação (e reconhecimento dessa circulação) deles nos grandes centros urbanos foi uma constante por todo o século XX e antes. ${ }^{2}$

Ainda no campo teórico-metodológico, era 
de se esperar uma análise mais rica de temas como a manipulação da gestualidade, do vocabulário e do vestuário. Mesmo que nos filmes analisados esses elementos sejam de fato exacerbados e conduzam à construção de personagens homossexuais estereotipados, não se pode esquecer que o uso do escracho e do deboche também é uma das formas que as minorias detêm de se fazerem ver e de criticarem uma ordem vigente para elas indesejada. Tal uso talvez também pudesse ser lido, sem embargo da existência de preconceito e discriminação, como uma das poucas alternativas disponíveis aos diretores para que pudessem dar voz a figuras homossexuais. Isso não é examinado pelo autor. Uma aproximação com os estudos de Mikhail Bakthin, por exemplo, teria levado o autor a olhar para essas questões de um patamar diferenciado. Tivesse servido-se desses estudos, teria ainda examinado o "poder que o cinema exerce sobre o pensamento das pessoas" (p. 36) de forma mais circular e elástica, lembrando que as audiências reconstroem significados e atribuem sentidos diferentes aos discursos e imagens que lhes são apresentados.

Mas talvez o grande problema do livro esteja situado na forma como é criticada a representação do homossexual no cinema. Ao opor-se à exposição de tipos afeminados e marginais, o autor não visualiza que esses não são somente criações de diretores e autores nem produtos de um olhar preconceituoso da nossa sociedade. São figuras reais que, com suas crises e histórias dramáticas, habitam a cultura homossexual brasileira e que, portanto, também têm direito a serem apresentadas e representadas. Até porque, ontem e hoje, aqui e alhures, são justamente os tipos mais 'desviantes' que normalmente assumem a linha de frente nos enfrentamentos mais duros pelos direitos gays. Nesse domínio a argumentação de Moreno aproxima-se bastante de um discurso que, ao buscar desconstruir uma imagem negativa fixada, sugere um novo 'modelo' de homossexual (despido de trejeitos, profissional, 'sexualmente responsável', etc.) ajustado à organização de gênero que hoje conhecemos. ${ }^{3} \mathrm{~A}$ nosso ver talvez fosse uma causa mais justa advogar por espaço para que todos - gays efeminados e masculinos, desviantes e adaptados aos padrões sociais predominantes - fossem igualmente representados.

1 BOURDIEU, Pierre. Sobre a televisão. Rio de Janeiro: Jorge Zahar, 1997. p. 28.

${ }^{2}$ Sobre tal circulação ver: GREEN, James. Além do caranaval: a homossexualidade masculina no Brasil do século XX. São Paulo: UNESP, 2000; e MOTT, Luiz. Homossexuais da Bahia: dicionário biográfico. Salvador: Editora Grupo Gay da Bahia, 1999.

${ }^{3}$ Para uma análise, a partir da experiência americana, das implicações políticas e culturais - em especial a exclusão - contidas nos esforços de certos setores do movimento gay em recriar a figura do "bom homossexual", ver GÓIS, J. B. H. "A conservadorização do discurso anti-AIDS nos Estados Unidos". Revista Serviço Social e Sociedade, n. 58, 1998.

JOÃO BÔSCO HORA GÓIS Universidade Federal Fluminense

\section{Feministas interrogam os estudos de religião}

\author{
Feminism and Religion, an \\ Introduction.
}

GROSS, Rita.

Boston, Beacon Press, 1996. 279 p.

A autora dessa obra é professora de Filosofia e Estudos Religiosos na Universidade de WisconsinEau Claire, nos Estados Unidos. O livro Feminism and Religion, an Introduction organiza-se em seis capítulos. É apresentado pela autora como um estudo "cross-cultural", característica inerente à disciplina Estudos de Religião, não se limitando às religiões ou às teologias cristãs e pós-cristãs, nem ao feminismo ocidental. Gross propõe-se a realizar, com essa obra, duas tarefas, que considera cruciais aos estudos de feminismo e religião: oferecer informações sobre os papéis religiosos das mulheres e identificar a perspectiva feminista em cada uma das religiões estudadas. Sua abordagem é, ao mesmo tempo, descritiva e normativa. A autora pretende mostrar o que acontece quando métodos feministas são aplicados aos dados de pesquisas sobre religiões 